\title{
MAKING A DIFFERENCE: REFLECTIONS ON KNOWLEDGE MOBILIZATION IN PROVINCIAL RURAL POLICY
}

\author{
Ashleigh Weeden
}

PhD Student | School of Environmental Design \& Rural Development, University of Guelph 


\section{Everybody wants to be the first to go second.}


- Public policy = anything governments do or do not do (Reimer \& Bollman, 2009)

- Policy analysis can be for policy or of policy and seeks to provide alternative choices for policy makers (Colebatch, 2016; GIll \& Saunders, 1992)

- Relatively recent endeavour, stemming from large-scale planning \& public financial management of $1960 \mathrm{~s}$ (Gill \& Saunders, 1992)

- Often focused on macro-level processes that don't capture the micro-level human activities that underpin the mechanics of policy formation (Dunlop \& Radaelli, 2017)

- We tend to focus on the engine and not on the mechanics that maintain it 


\section{WHAT'S THE EVIDENCE ON EVIDENCE-}

BASED POLICY?

- Policy making neither begins nor ends with seemingly straightforward decisions about allocating resources: policy choices in the face of competing needs, goals \& aspirations influences both the means and the ends of the policy process (Atkinson \& Chandler, 1983)

- Very few studies that assess the practical importance of influence of what enables or creates barriers to knowledge mobilization in public policy (Oliver et al., 2014)

- Collectively, we're often fuzzy on what we mean by policy, evidence, policy-makers, policy-making, and the specific mechanics of a given policy cycle at each jurisdiction 


\section{You keep using that word.}

I do not think it means

what you think it means.

- Inigo Montoya 


\section{WHAT DOES THIS MEAN FOR CANADIAN PROVINCIAL RURAL POLICY?}

- Interviewed policy makers from Ontario, Prince Edward Island, and Newfoundland and Labrador

- Interviewees included former senior policy makers, junior policy analysts, and policy advocates external to government

- Five key challenges identified to effectively using research evidence:

- Difficulty accessing research evidence

- Ineffective knowledge translation tools

- Misalignment of academic research with policy needs

- Slow research cycle versus fast policy cycle

- Lack of political will to implement research findings 


\section{RECONSIDERING EVIDENCE-BASED RURAL POLICY}

- Interviews reinforce broader literature findings that: "timely access to good quality and relevant research evidence, collaborations with policymakers and relationship- and skillsbuilding with policymakers are reported to be the most important factors in influencing the use of evidence." (Oliver et al., 2014)

- Evidence-based policy analysis seeks to avoid or limit policy failures generated from disconnects between government expectations and actual conditions in communities

- However: movement to incorporate more and better evidence in the policy process hasn't effectively altered the policy cycle (Newman, 2017; Newman, Cherney, \& Head, 2017)

- Need to develop clarity \& consistency in terms of what constitutes evidence and matching program goals with policy instruments 
We're not going to save the world by email, you really have to come over

and say "hello."

- Robert Swan 


\title{
QUESTIONS?
}

\section{LEARN MORE AT WWW.RURALDEV.CA/MAKING-A-DIFFERENCE}

\author{
OR CONTACT \\ ASHLEIGH WEEDEN WEEDENS@UOGUELPH.CA
}

This project is funded by the Ontario Ministry of Agriculture, Food and Rural Affairs through the Ontario Agri-Food Innovation Alliance 